\title{
Novel Carbon Nanoparticles Derived from Biodiesel Soot as Lubricant Additives
}

\author{
Chuan $\mathrm{Li}^{1,2}{ }^{\mathbb{D}}$, Mingling $\mathrm{Li}^{1, *}$, Xinyun Wang ${ }^{1}$, Weimin Feng ${ }^{2}$, Qiangqiang Zhang ${ }^{2}$, Bo $\mathrm{Wu}^{2}$ and \\ Xianguo $\mathrm{Hu}^{2}$,*(D) \\ 1 School of Chemistry and Material Engineering, Chaohu University, Hefei 238000, China \\ 2 School of Mechanical Engineering, Hefei University of Technology, Hefei 230009, China \\ * Correspondence: 053014@chu.edu.cn (M.L.); xghu@hfut.edu.cn (X.H.); Tel.: +86-551-82363257 (M.L.); \\ +86-551-62901359 (X.H.)
}

Received: 16 July 2019; Accepted: 30 July 2019; Published: 3 August 2019

\begin{abstract}
The objective of this study was to investigate the roles and tribological mechanisms of onion-like carbon nanoparticles derived from biodiesel soot (BDS) when applied in water $\left(\mathrm{H}_{2} \mathrm{O}\right)$ and liquid paraffin (LP). In this study, we prepared nitric acid-treated BDS (NA-BDS) as an additive to $\mathrm{H}_{2} \mathrm{O}$ and NA-BDS modified with oleylamine (NA-BDS-OLA) as an additive to LP. Raman spectroscopy, field-emission transmission electron microscopy, Fourier transform infrared spectroscopy, and zeta potentiometry were used to characterize the results of the nitric acid treatment and oleylamine modification. The tribological behaviors and corresponding mechanisms of the new onion-like carbon nanoparticles were evaluated using a ball-on-disc reciprocating tribometer, as well as field-emission scanning electron microscopy, three-dimensional laser scanning microscopy, and Raman spectroscopy. The results indicated that the additives NA-BDS and NA-BDS-OLA, which were onion-like carbon nanoparticles with sizes ranging from 35 to $40 \mathrm{~nm}$, enhanced the antiwear and friction reduction properties of $\mathrm{H}_{2} \mathrm{O}$ and LP, respectively. Through tribo-mechanisms, these types of soot can serve as spacers and ball bearings between the rubbing surfaces. Moreover, exfoliation under a high load as a result of the formation of a graphitic layer facilitates easy shearing.
\end{abstract}

Keywords: biodiesel soot; carbon nanoparticles; onion-like; lubricant additive

\section{Introduction}

With changes in the global climate and with the growing energy demand, there has been an increased interest in renewable fuels for the replacement of petroleum. Biodiesel is a potential renewable fuel source. Biodiesel (fatty acid alkyl ester) can be obtained via the transesterification process [1]. It exhibits characteristics comparable to those of petroleum diesel, as well as a low sulfur amount, low aromatics, low viscosity, a high flash point, high lubricity, and a high cetane number [2]. Although biodiesel has a higher oxygen amount than petroleum diesel, which can enhance its combustion efficiency, biodiesel soot (BDS) is still emitted [3,4].

Soot can contaminate the lubricating oil within the sump as a result of the blow-by gasses [5]. Soot in the lubricating oil can increase the viscosity of the oil and affect its tribological properties. Salehi et al. [6] found that rapid tribofilm formation through the addition and removal of ZDDP (Zinc Dialkyl Dithiophosphates)by soot particles results in severe wear, which can be attributed to the corrosive-abrasive mechanism. Green et al. [7] concluded that a larger soot amount in the lubricating oil generates more wear, which is mainly due to the abrasive process. However, soot also has potential as a lubricant additive. Guo et al. [8] reported that the anti-wear and friction-reduction properties of PAO (Polyalphaolefin) 4 oil were improved by adding $0.01 \mathrm{wt} \%$ diesel soot. Additionally, carbon nano-onions have been widely studied as lubrication additives because they can improve the 
tribological properties of oils. Joly-Pottuz et al. [9] found that carbon nano-onions have no dangling bonds on their surface and can therefore easily slide and even roll on a friction surface. Hirata et al. [10] reported that the closed structure of carbon nano-onions provides good mechanical strength. BDS contains short grapheme segments of high tortuosity [11,12], which exhibit great potential for the development of onion-like carbon nanoparticles. However, to the best of our knowledge, few reports have described onion-like carbon nanoparticles derived from BDS as a lubricant additive.

At present, real engine soot is expensive and not widely available because it can only be produced by running an engine for a long time under suboptimal conditions [13]. Thus, engine soot alternatives (such as carbon black and self-prepared soot) are typically used to research the effect of engine soot on the lubricating oils [14,15]. Clague et al. reported that diesel engine soot and carbon black exhibited similar primary particle sizes and internal structures of particulates [16]. Ferraro et al. used various techniques to compare carbon black and diesel engine soot and found that carbon black was an appropriate substitute for engine diesel soot [17]. Alternatively, self-prepared soot can be used as an engine-soot alternative. Self-prepared soot was prepared via the combustion of fuel at a normal temperature and the atmospheric pressure [18]. Hu et al. compared the differences between carbon black and self-prepared biomass-oil soot. Differences were observed in the elemental composition and the functional groups. However, self-prepared biomass-oil soot is similar in size, morphology, and internal structure to carbon black [19]. Studies have indicated that self-prepared BDS has discontinuous graphitic layers and that the graphitic layers are surrounded by an amorphous phase [20]. This structure is similar to that of real BDS from a diesel engine [21,22]. Thus, self-prepared BDS can be used as an alternative to real BDS.

In this study, onion-like carbon nanoparticles derived from BDS were prepared. The tribological properties of nitric acid-treated BDS (NA-BDS) as an additive in water $\left(\mathrm{H}_{2} \mathrm{O}\right)$ and NA-BDS modified with oleylamine (NA-BDS-OLA) as an additive in liquid paraffin (LP) were investigated. The corresponding tribological mechanisms were also examined. Thus, the objective of this study was to provide a new path for recycling carbon resources from engine emissions and for reducing environmental pollution from fuel combustion.

\section{Materials and Methods}

\subsection{Sample Preparation}

All reagents were analytical-grade. Methanol (Sinopharm Chemical Reagent Co., Ltd., Shanghai, China), Oleylamine (Aladdin Industrial Co., Ltd., Shanghai, China), Ethanol (China Sun Specialty Products Co., Ltd., Changshu, China), Nitric acid (68\%, Sinopharm Chemical Reagent Co., Ltd., Shanghai, China). And soybean oil was obtained from China Oil \& Food Stuffs Corporation (Beijing, China).Ultrapure water obtained from a water purification system (UPT-11-10T, Sichuan Ulupure Super Pure Technology Co., Ltd., Chengdu, China) was used in all experiments. Biodiesel was synthesized through transesterification between methanol and soybean oil using a calcium-based catalyst. The physical properties are presented in Table 1 . The procedure for collecting BDS was as follows [23,24]: (1) First, $80 \mathrm{~cm}^{3}$ of biodiesel was poured into a $100 \mathrm{~cm}^{3}$ ceramic crucible, and then the ceramic crucible was placed on an iron stand. (2) Clean glass slides (BDS capturing slides) were used as substrates to collect the BDS. The glass slides were clamped on the upper part of the iron stand, above the ceramic crucible. When the biodiesel was ignited, the slide was kept over the flame at a distance of $2 \mathrm{~cm}$. (3) As the biodiesel burned, the BDS in the flame was deposited onto the slide surface. When the biodiesel in the ceramic crucible was completely burned and a BDS layer with a thickness of a few micrometers was deposited on the glass slide, the BDS layer was carefully removed using a laboratory spoon and collected in a glass bottle. (4) Finally, the collected BDS was dried at $120^{\circ} \mathrm{C}$ for $3 \mathrm{~h}$ and ground into a fine granular powder. Burning $1 \mathrm{~kg}$ of biodiesel yielded 13-18 $\mathrm{g}$ of BDS. 
Table 1. Physical properties of the biodiesel.

\begin{tabular}{ccc}
\hline Property & Value & Methods \\
\hline Density at $20^{\circ} \mathrm{C}, \mathrm{kg} \cdot \mathrm{m}^{-3}$ & 875 & ASTM D4052 \\
Flash point (closed up), ${ }^{\circ} \mathrm{C}$ & 168 & ASTM D93 \\
Acid value, $\mathrm{mgKOH} \cdot \mathrm{g}^{-1}$ & 0.045 & ASTM D664 \\
Kinematic viscosity at $40{ }^{\circ} \mathrm{C}, \mathrm{mm}^{2} \cdot \mathrm{s}^{-1}$ & 4.5 & ASTM D445 \\
Water content, $\%$ & Trace & ASTM D1744 \\
\hline
\end{tabular}

A total of $0.2 \mathrm{~g}$ of BDS was suspended in $30 \mathrm{~g}$ of concentrated nitric acid (68\%, analytical reagent) and refluxed for $20 \mathrm{~h}$ in an oil bath maintained at $80^{\circ} \mathrm{C}$. After repeated centrifugation and washing with ultrapure water, it was then dried at $120^{\circ} \mathrm{C}$ for $10 \mathrm{~h}$. The product was denoted as NA-BDS. Then, $0.1 \mathrm{~g}$ of NA-BDS was refluxed in $5 \mathrm{~g}$ of oleylamine (OLA) at $110^{\circ} \mathrm{C}$ for $12 \mathrm{~h}$. The mixture was purified through repeated washings with ethanol using centrifugation. Finally, it was dried at $120^{\circ} \mathrm{C}$ for $5 \mathrm{~h}$. The product was denoted as NA-BDS-OLA. As additives, BDS and NA-BDS (at concentration levels of $0.1,0.2$, and $0.3 \mathrm{wt} \%$ ) were added to the $\mathrm{H}_{2} \mathrm{O}$. Moreover, BDS and NA-BDS-OLA (at concentration levels of $0.2,0.3$, and $0.4 \mathrm{wt} \%$ ) were added to the LP. The mixtures were then distributed using a glass rod for $15 \mathrm{~min}$, followed by magnetic stirring for $1 \mathrm{~h}$ to reduce any deviations in the experiment.

\subsection{Tribological Testing and Characterization}

Tribological testing was performed using a ball-on-disc reciprocating tribometer (CFT-I, Lanzhou Zhongke Kaihua Technology Development Co. Ltd., Lanzhou, China). The upper ball samples ( $\Phi$ $6 \mathrm{~mm}$, surface roughness of $\left.R_{\mathrm{a} 1}=0.02 \mu \mathrm{m}\right)$ and lower disk samples $(50 \mathrm{~mm} \times 50 \mathrm{~mm} \times 5 \mathrm{~mm}$, surface roughness of $R_{\mathrm{a} 2}=0.5 \mu \mathrm{m}$ ) were made of GCr15 steel with a hardness of 62-65 HRC (Rockwell hardness value). The lower disk samples were fixed, and the upper ball samples were slid in a reciprocating manner with a sliding distance of $5 \mathrm{~mm}$. The friction pairs of the ball-on-disk reciprocating tribometer are illustrated in Figure 1. The wear rate is estimated by Archard's equation. As the initial roughness of the lower disk samples was high, the wear volume of disc samples was very difficult to assess [6]. Therefore, the wear volume of upper ball samples was used to calculate the wear rate. In order to determine the wear rate of the upper ball samples, the following Equations (1), (2), and (3) were used [25]:

$$
\begin{gathered}
V=\pi \times h \times\left(0.75 d^{2}+h^{2}\right) / 6, \\
h=R-\left(R^{2}-0.25 d^{2}\right)^{0.5}, \\
K_{B}=V /(L \times F),
\end{gathered}
$$

where $K_{B}$ represents ball wear rate (in $\mathrm{mm}^{3} / \mathrm{N} \cdot \mathrm{m}$ ), $d$ represents the diameter of the wear scar of the upper ball (in $\mathrm{mm}$ ), $h$ represents the height of the wear of the upper ball (in $\mathrm{mm}$ ), $R$ represents the radius of the upper ball (in $\mathrm{mm}$ ), $V$ represents the wear volume of the upper ball sample (in $\left.\mathrm{mm}^{3}\right), L$ represents the sliding distance (in $\mathrm{m}$ ), and $F$ represents the applied load (in $\mathrm{N}$ ). Each tribological test was repeated three times to obtain a standard deviation and to reduce human error.

For the ball-on-disc contact, the Hertz contact diameter and the contact stress were calculated using Hertz's theory [26]:

$$
\begin{gathered}
a=2 \times\left(\frac{2}{3} \times \frac{W \times R}{E^{\prime}}\right)^{\frac{1}{3}}, \\
P=\frac{4 \times W}{\pi \times \mathrm{a}^{2}}
\end{gathered}
$$

where $a$ represents the Hertz contact diameter, $W$ represents the normal load $(=20 \mathrm{~N}, 50 \mathrm{~N}, 100 \mathrm{~N}), R$ represents the equivalent radius of curvature $(3 \mathrm{~mm})$, and $E^{\prime}$ represents the effective elastic modulus (233 GPa). Thus, the Hertz diameter was $1.11 \times 10^{-4} \mathrm{~m}, 1.51 \times 10^{-4} \mathrm{~m}$, and $1.90 \times 10^{-4} \mathrm{~m}$, and the contact stress was $2 \mathrm{GPa}, 2.8 \mathrm{GPa}$, and $3.5 \mathrm{GPa}$. 

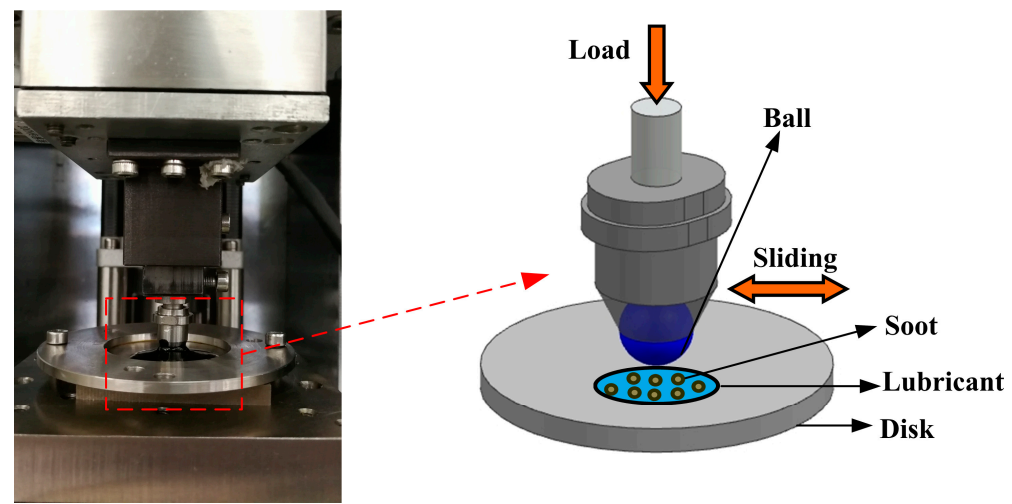

Figure 1. Configuration of the friction pairs of the ball-on-disk reciprocating tribometer.

The $\lambda$ was calculated using Dowson and Hamrock's minimum film thickness formula:

$$
\begin{gathered}
h_{\min }=3.63 \times R \times \frac{G^{* 0.49} \times U^{* 0.68}}{W^{* 0.073}}\left(1-e^{-0.68 k}\right), \\
\lambda=\frac{h_{\min }}{\sqrt{R a_{1}^{2}+R a_{2}^{2}}}, \\
G^{*}=\alpha \times E^{\prime}, \\
U^{*}=\frac{\eta_{0} \times U}{E^{\prime} \times R}, \\
W^{*}=\frac{W}{E^{\prime} \times R^{2}},
\end{gathered}
$$

where $R$ represents the equivalent radius of curvature $(=3 \mathrm{~mm}), k$ is the elliptical parameter $(\approx 1)$, $\eta_{0}$ represents the dynamic viscosity of water or $\mathrm{LP}\left(1 \times 10^{-3}\right.$ or $100.2 \times 10^{-3} \mathrm{Ns} / \mathrm{m}^{2}$, respectively $), U$ represents the sliding speed $(=50 \mathrm{~mm} / \mathrm{s}), E^{\prime}$ represents the effective elastic modulus (= $\left.233 \mathrm{GPa}\right), \alpha$ is the coefficient of viscosity-pressure of water and liquid paraffin, respectively, $\left(2.2 \times 10^{-8} \mathrm{~m}^{2} / \mathrm{N}\right.$ or $\left.2 \times 10^{-8} \mathrm{~m}^{2} / \mathrm{N}\right)[27,28]$, and $R_{\mathrm{a} 1}$ and $R_{\mathrm{a} 2}$ represent the surface roughness values of the ball and disc, respectively $\left(R_{\mathrm{a} 1}=0.02 \mu \mathrm{m}, R_{\mathrm{a} 2}=0.5 \mu \mathrm{m}\right)$.

The maximum value of $\lambda(W=20 \mathrm{~N})$ was calculated to be 0.0019 and 0.0418 under water and LP lubrication, respectively, for the test conditions. This confirms that the sliding tests were conducted in the boundary lubrication regime.

The morphologies of BDS, NA-BDS, and NA-BDS-OLA were examined using Raman spectroscopy (HR Evolution, Horiba Jobin Yvon, Paris, France), field-emission transmission electron microscopy (FETEM, JEM-2100F, JEOL, Tokyo, Japan), and Fourier transform infrared (FTIR) spectroscopy (Nicolet6700, Thermo Nicolet, Madion, WI, USA). The particle-size distributions of BDS and NA-BDS in $\mathrm{H}_{2} \mathrm{O}$, as well as those of BDS and NA-BDS-OLA in LP, were characterized using a zeta potentiometer (Nano-ZS90, Malvern, Worcestershire, UK). After friction and wear tests, the friction surfaces were inspected and analyzed using field-emission scanning electron microscopy (FESEM, SU8010, Hitachi, Tokyo, Japan), three-dimensional laser scanning microscopy (VK-X100, Keyence, Osaka, Japan), and Raman spectroscopy.

\section{Results and Discussion}

\subsection{Characterization}

To investigate the effects of nitric acid treatment and oleylamine (OLA) modification on BDS, Raman spectroscopy, FETEM, FTIR spectroscopy, and particle-size distribution analyses were conducted. 
The Raman spectra of BDS, NA-BDS, and NA-BDS-OLA are presented in Figure 2. The Raman spectra exhibited well-defined D and G peaks. The D peak (at $\sim 1346 \mathrm{~cm}^{-1}$ ) is attributed to the defects and disordered graphitic lattices. The G peak (at $\left.\sim 1589 \mathrm{~cm}^{-1}\right)$ is attributed to the graphitic lattices $[29,30]$. In general, the $\mathrm{I}_{\mathrm{D}} / \mathrm{I}_{\mathrm{G}}$ ratio increased with the increase in the degree of disorder. A comparison of the Raman spectra of BDS and NA-BDS indicated that the $\mathrm{I}_{\mathrm{D}} / \mathrm{I}_{\mathrm{G}}$ ratio of the NA-BDS (2.546) was lower than that of BDS (2.956). The $\mathrm{I}_{\mathrm{D}} / \mathrm{I}_{\mathrm{G}}$ ratio of NA-BDS-OLA (2.559) was similar to that of NA-BDS (2.546). The spectroscopic results indicated that nitric acid treatment improved the order of BDS.

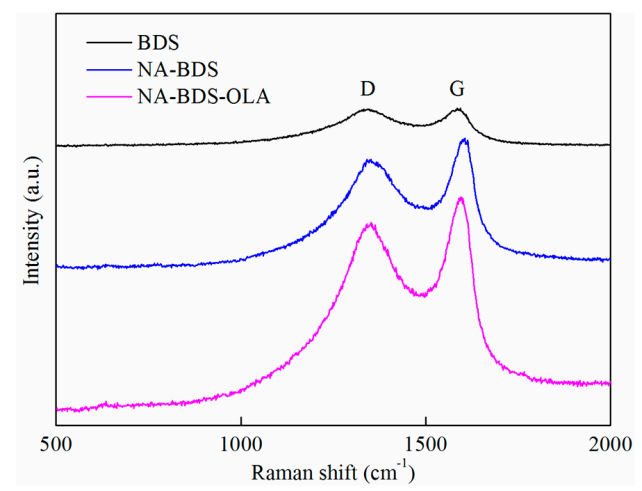

Figure 2. Raman spectra of biodiesel soot (BDS), nitric-acid-treated BDS (NA-BDS), and NA-BDS modified with oleylamine (NA-BDS-OLA).

The Raman results were complemented with FETEM observations of BDS, NA-BDS, and NA-BDS-OLA, as shown in Figure 3. The diameters of BDS, NA-BDS, and NA-BDS-OLA were approximately $35-40 \mathrm{~nm}$. For BDS, short, disconnected, and concentrically-oriented graphitic layers were observed, as shown in Figure 3a. However, these graphitic layers were surrounded by amorphous phases. As shown in Figure 3b,c, compared with BDS, the apparent growth of highly curved and discontinuous graphitic layers was observed in NA-BDS and NA-BDS-OLA, respectively, which were structurally similar to onion-like carbon. A statistical evaluation of the FETEM micrographs indicated that the degree of graphitization was higher for NA-BDS and NA-BDS-OLA than that for BDS, in agreement with the Raman results [31].
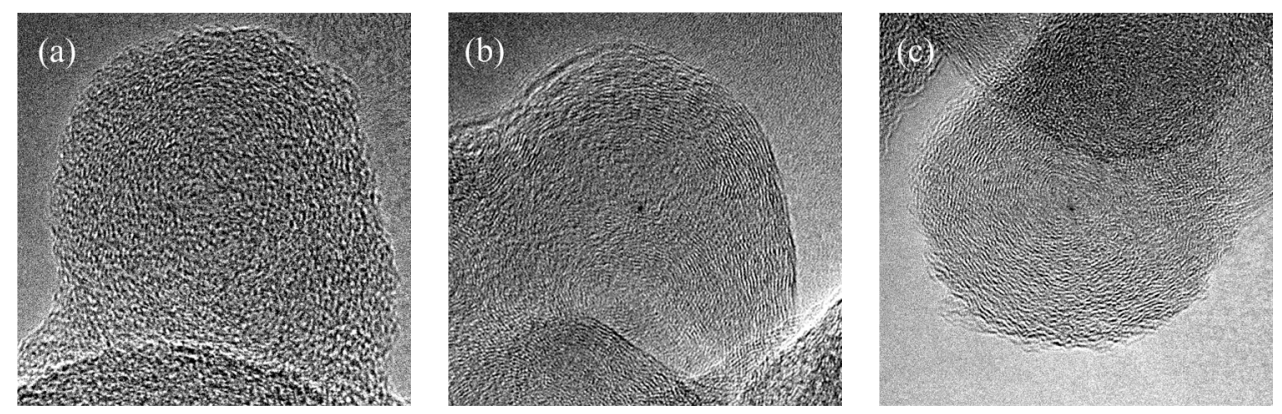

Figure 3. Field-emission transmission electron microscopy (FETEM) micrographs of (a) BDS, (b) NA-BDS, and (c) NA-BDS-OLA.

As shown in Figure 4, the functional groups on the surfaces of OLA, BDS, NA-BDS, and NA-BDS-OLA were investigated using FTIR spectroscopy. For BDS, the three main peaks at 1221, 1602 , and $3443 \mathrm{~cm}^{-1}$ are ascribed to the $\mathrm{C}-\mathrm{O}-\mathrm{C}, \mathrm{C}=\mathrm{C}$, and $\mathrm{C}-\mathrm{OH}$ stretching vibrations, respectively. For NA-BDS, the peaks at $\left(1535 \mathrm{~cm}^{-1}\right.$ and $\left.1726 \mathrm{~cm}^{-1}\right)$ and $1347 \mathrm{~cm}^{-1}$ are attributed to the stretching vibrations of $\mathrm{C}=\mathrm{O}$ and $\mathrm{C}-\mathrm{O}$, respectively, indicating that strong $(-\mathrm{COOH})$ polar groups were introduced into the NA-BDS through the nitric acid treatment [31]. For OLA, the main peaks in the spectrum are related to $-\mathrm{CH}_{2}-\left(1465 \mathrm{~cm}^{-1}\right.$ and $\left.2853 \mathrm{~cm}^{-1}\right)$ and $-\mathrm{CH}_{3}\left(2923 \mathrm{~cm}^{-1}\right)$. Moreover, for NA-BDS-OLA, the 
peaks at 2853 and $2923 \mathrm{~cm}^{-1}$ are associated with $-\mathrm{CH}_{2}-$ and $-\mathrm{CH}_{3}$ stretching vibrations, respectively, indicating that the surface of NA-BDS-OLA contained long-carbon-chain lipophilic groups owing to the OLA treatment [32]. This was because of the many active hydroxyl and carboxyl groups of NA-BDS which can adsorb and react with OLA. Interestingly, the peak shape of C-H under NA-BDS-OLA became narrower than OLA, indicating that the $\mathrm{C}-\mathrm{H}$ content of NA-BDS-OLA was smaller than OLA.

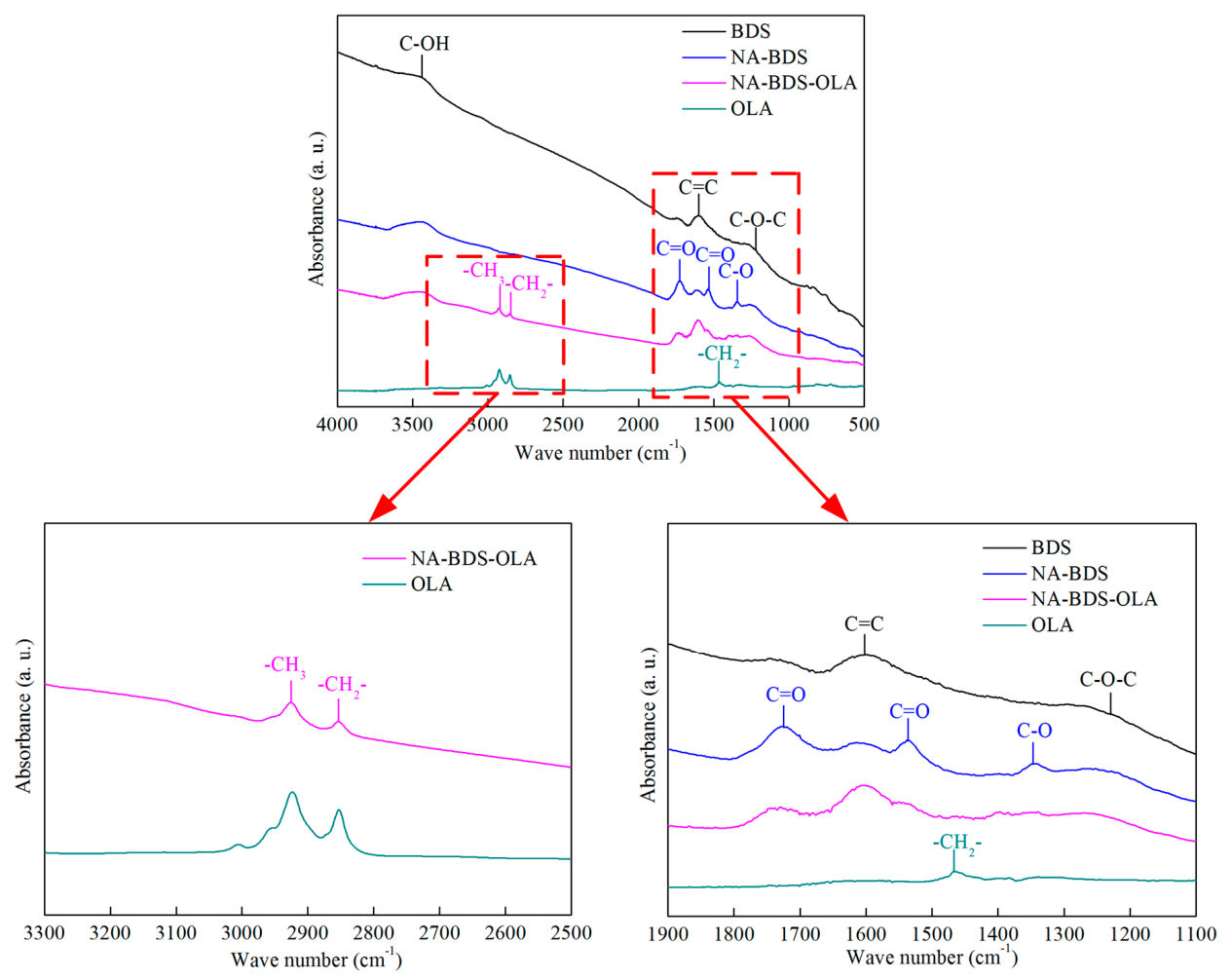

Figure 4. Fourier transform infrared (FTIR) spectra of oleylamine (OLA), BDS, NA-BDS, and NA-BDS-OLA.

The particle-size distributions of the different soot samples are presented in Figure 5. As shown in Figure 5a, the particle size of $\mathrm{BDS}$ in $\mathrm{H}_{2} \mathrm{O}$ ranged from 91.3 to $615.1 \mathrm{~nm}$, with a mean value of $219.7 \mathrm{~nm}$. Compared with BDS, the mean particle size of NA-BDS in $\mathrm{H}_{2} \mathrm{O}$ was reduced to $185.3 \mathrm{~nm}$, whereas the particle size of NA-BDS in $\mathrm{H}_{2} \mathrm{O}$ ranged from 78.8 to $531.2 \mathrm{~nm}$. This phenomenon was due to the oxidation of BDS, which increased the amount of hydrophilic functional groups in NA-BDS [31], and stabilized the material in $\mathrm{H}_{2} \mathrm{O}$. As indicated by Figure $5 \mathrm{~b}$, the mean particle size decreased from $200.5 \mathrm{~nm}$ (between 122.4 and $396.1 \mathrm{~nm}$ for BDS in LP) to $130.4 \mathrm{~nm}$ (between 68.1 and $295.3 \mathrm{~nm}$ for NA-BDS-OLA in LP), which is ascribed to the introduction of functional groups with high lipophilicity on the surface of NA-BDS-OLA [33]. These results agree well with the FTIR measurements. 

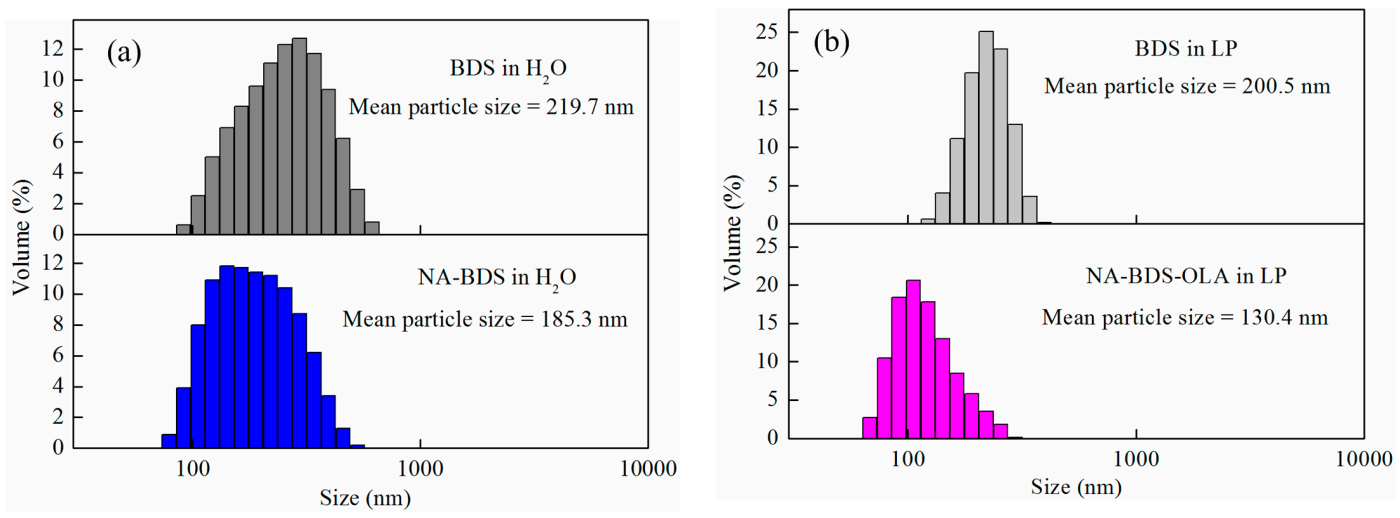

Figure 5. Particle-size distributions of (a) BDS and NA-BDS in $\mathrm{H}_{2} \mathrm{O}$, and (b) BDS and NA-BDS-OLA in liquid paraffin (LP).

\subsection{Tribological Performance of Soot Samples in $\mathrm{H}_{2} \mathrm{O}$}

The evolutions of the average friction coefficient and wear rates for lubrication with different amounts of two types of soot in $\mathrm{H}_{2} \mathrm{O}$ are plotted in Figure 6. Clearly, both BDS and NA-BDS reduced the friction and wear for all the tested concentrations. $\mathrm{H}_{2} \mathrm{O}+\mathrm{NA}-\mathrm{BDS}$ exhibited the best lubrication performance. At the optimum concentration of $0.2 \mathrm{wt} \%$, the friction coefficients and wear rates of $\mathrm{H}_{2} \mathrm{O}+\mathrm{NA}-\mathrm{BDS}$ were reduced by $52.5 \%$ and $66.9 \%$, respectively, compared with that lubricated using $\mathrm{H}_{2} \mathrm{O}$. This indicates that, at different amounts, BDS and NA-BDS can improve the friction and wear behaviors of $\mathrm{H}_{2} \mathrm{O}$, and that NA-BDS is more effective than BDS.
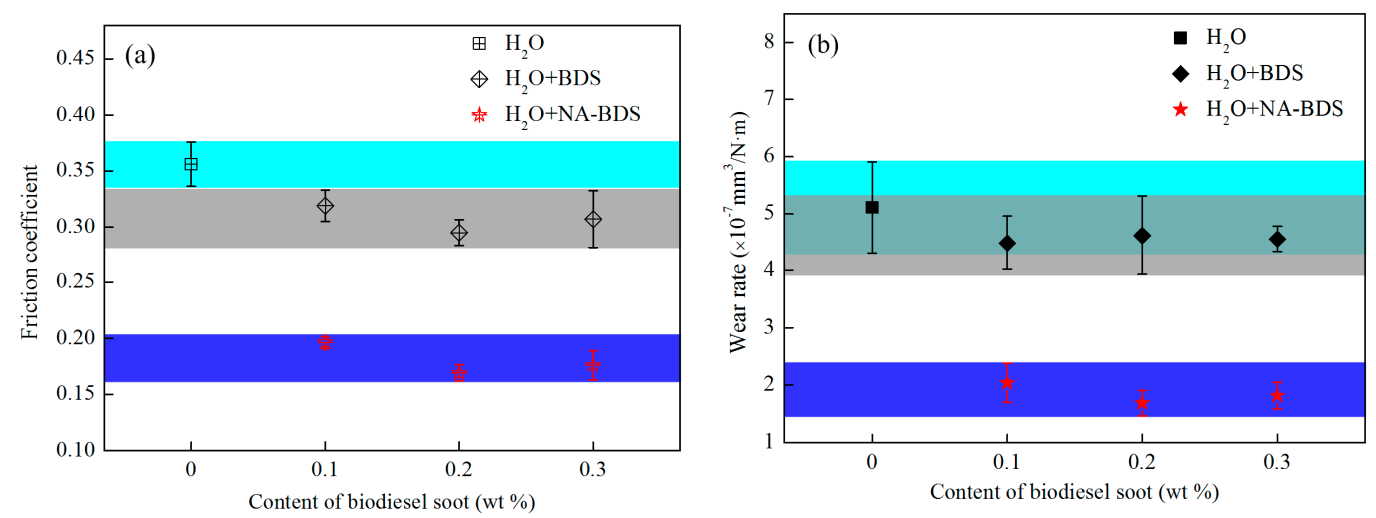

Figure 6. Evolutions of the (a) average friction coefficient and (b) wear rates for lubrication with different amounts of BDS and NA-BDS in $\mathrm{H}_{2} \mathrm{O}(\mathrm{load}=50 \mathrm{~N}$, speed $=50 \mathrm{~mm} / \mathrm{s}$, duration $=30 \mathrm{~min})$.

The evolutions of the average friction coefficient and the wear rates for lubrication with the two types of soot in $\mathrm{H}_{2} \mathrm{O}$ at different loads are shown in Figure 7. Under the different loads, the friction coefficients and wear rates decreased in the following order: $\mathrm{H}_{2} \mathrm{O}>\mathrm{H}_{2} \mathrm{O}+\mathrm{BDS}>\mathrm{H}_{2} \mathrm{O}+$ NA-BDS. Thus, the anti-friction and anti-wear properties of $\mathrm{H}_{2} \mathrm{O}+$ NA-BDS were better than those of $\mathrm{H}_{2} \mathrm{O}+$ BDS and $\mathrm{H}_{2} \mathrm{O}$. Furthermore, BDS and NA-BDS enhanced the tribological performance of $\mathrm{H}_{2} \mathrm{O}$ from a low to high load, indicating that carbon nanoparticles (BDS and NA-BDS) entered the rubbing surfaces and performed their function, even under a high load. 

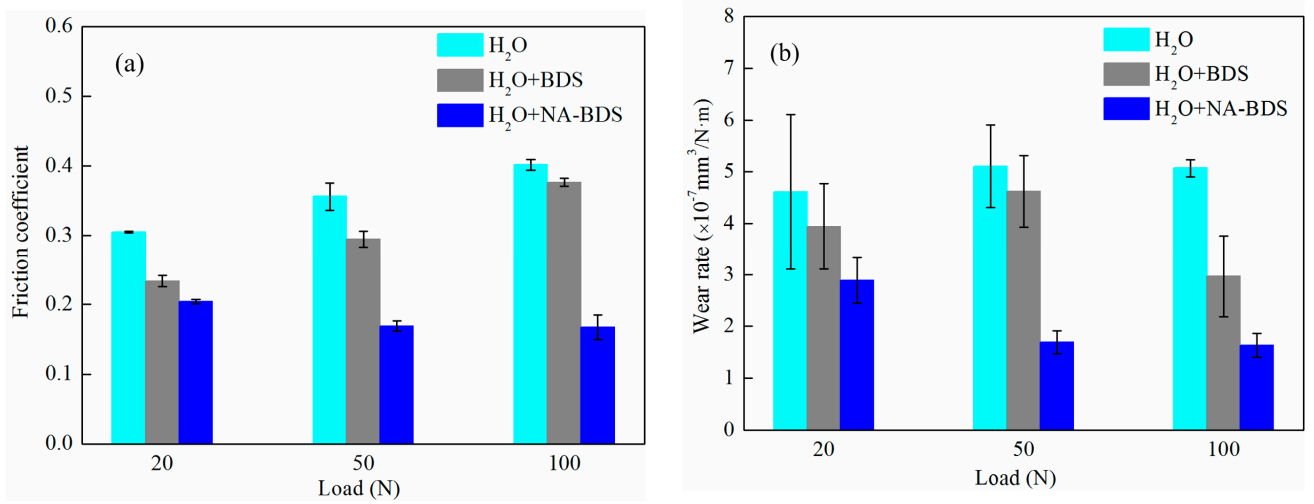

Figure 7. Evolutions of the (a) average friction coefficient and (b) wear rates for lubrication using BDS and NA-BDS in $\mathrm{H}_{2} \mathrm{O}$ at different loads (soot content $=0.2 \mathrm{wt} \%$, speed $=50 \mathrm{~mm} / \mathrm{s}$, duration $=30 \mathrm{~min}$ ).

Figure 8 shows FESEM images, optical micrographs, and corresponding worn surface profiles of the wear scars on the upper balls lubricated using $\mathrm{H}_{2} \mathrm{O}$, BDS $+\mathrm{H}_{2} \mathrm{O}$, and NA-BDS $+\mathrm{H}_{2} \mathrm{O}$. Comparing Figure $8 \mathrm{a}-\mathrm{c}$ reveals that the surface wear scars in the case of $\mathrm{H}_{2} \mathrm{O}$ had many corrosive pits and furrows [34]. When $0.2 \mathrm{wt} \% \mathrm{BDS}$ was added to $\mathrm{H}_{2} \mathrm{O}$, although the surface wear scars still exhibited many furrows, the number of corrosive pits was reduced. The worn surfaces of the upper balls lubricated using NA-BDS $+\mathrm{H}_{2} \mathrm{O}$ exhibited thin and shallow furrows and no corrosive pits. Compared with $\mathrm{H}_{2} \mathrm{O}$ and $\mathrm{H}_{2} \mathrm{O}+\mathrm{BDS}$, when $\mathrm{H}_{2} \mathrm{O}+\mathrm{NA}-\mathrm{BDS}$ was used as the lubricant, the surface roughness $R a$ of the worn surface of the ball was lower. Moreover, Figure $8 \mathrm{~d}$, which combines the optical micrographs in Figure 8a-c, indicates that the width and depth of the wear scar decreased in the following order: $\mathrm{H}_{2} \mathrm{O}>\mathrm{H}_{2} \mathrm{O}+\mathrm{BDS}>\mathrm{H}_{2} \mathrm{O}+$ NA-BDS. This indicates that $\mathrm{H}_{2} \mathrm{O}+$ NA-BDS had a better wear-resistance effect than $\mathrm{H}_{2} \mathrm{O}+\mathrm{BDS}$, in agreement with the results in Figure 7.
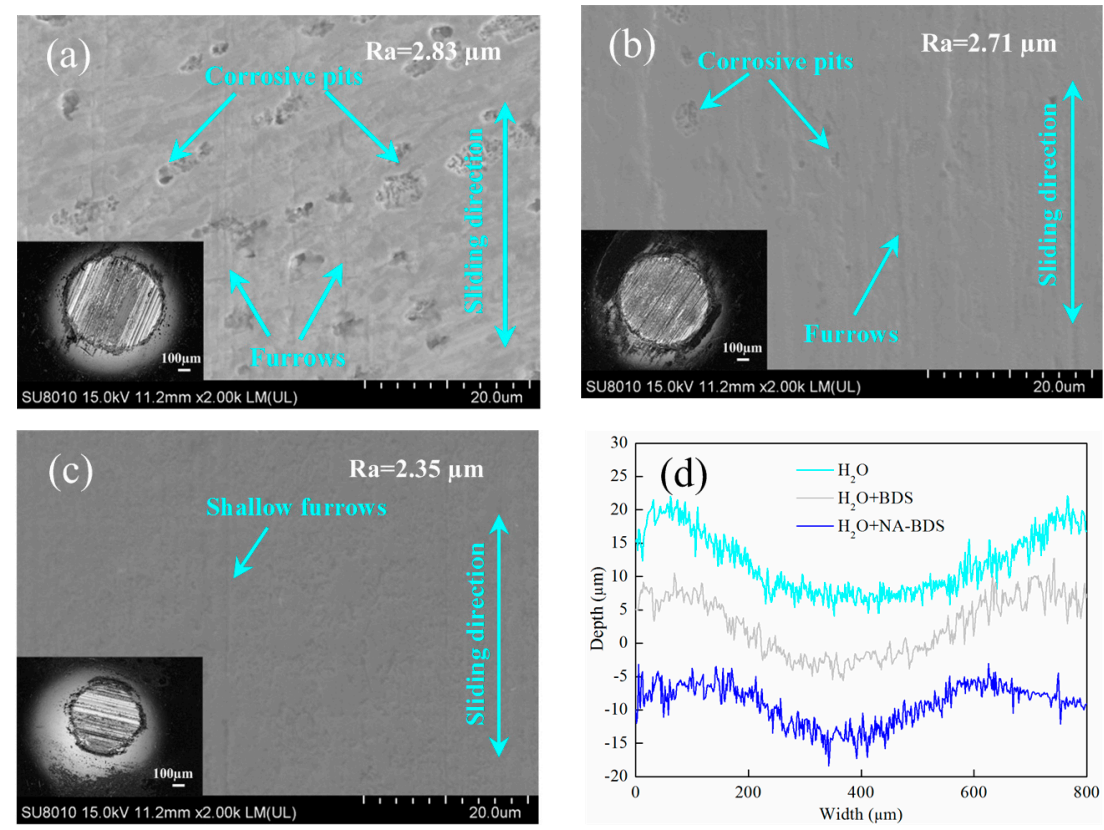

Figure 8. Field-emission scanning electron microscopy (FESEM) images and optical micrographs of wear scars on upper balls lubricated using (a) $\mathrm{H}_{2} \mathrm{O}$, (b) $\mathrm{H}_{2} \mathrm{O}+\mathrm{BDS}$, and (c) $\mathrm{H}_{2} \mathrm{O}+$ NA-BDS. (d) Corresponding worn surface profiles (soot content $=0.2 \mathrm{wt} \%$, load $=100 \mathrm{~N}$, speed $=50 \mathrm{~mm} / \mathrm{s}$, duration $=30 \mathrm{~min}$ ). 


\subsection{Tribological Performance of Soot Samples in LP}

The evolutions of the average friction coefficient and the wear rates for lubrication using different amounts of the two types of soot added to LP are presented in Figure 9. The friction coefficients and wear rates for LP + NA-BDS-OLA and LP + BDS were lower than those for LP. LP + NA-BDS-OLA exhibited the best tribological properties. At the optimum concentration of $0.3 \mathrm{wt} \%$, the friction coefficients and wear rates of LP + NA-BDS-OLA were $29.8 \%$ and $67.3 \%$ lower than those of LP, respectively. This indicates that at different amounts, BDS and NA-BDS-OLA can be used as lubrication additives for LP, and that LP + NA-BDS-OLA has better anti-friction and anti-wear properties than LP + BDS.
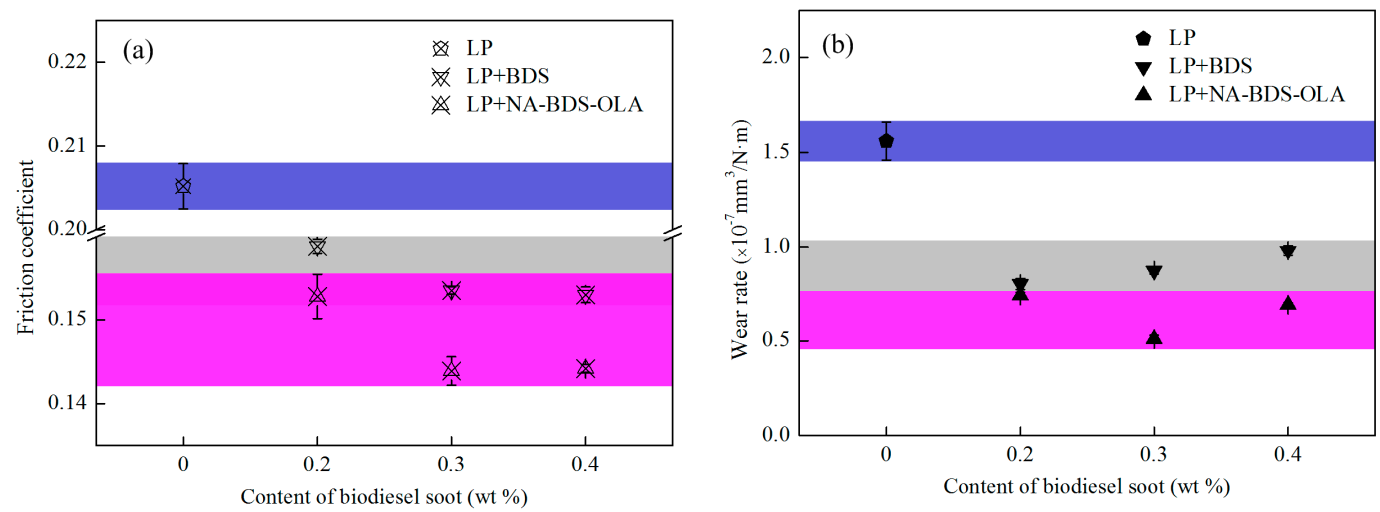

Figure 9. Evolutions of the (a) average friction coefficient and (b) wear rates for lubrication with different amounts of BDS and NA-BDS-OLA in LP (load $=100 \mathrm{~N}$, speed $=50 \mathrm{~mm} / \mathrm{s}$, duration $=30 \mathrm{~min})$.

Figure 10 shows the evolution of the average friction coefficient and wear rates for lubrication using the two types of soot in LP at different loads. The results indicate that the friction coefficients and wear rates for LP were the highest, followed by LP + BDS, and then LP + NA-BDS-OLA. Thus, LP + NA-BDS-OLA exhibited the best tribological performance. Interestingly, at a low load $(20 \mathrm{~N}, 50 \mathrm{~N})$, the lubricating property of LP was slightly improved with the addition of BDS and NA-BDS-OLA. However, at a high load $(100 \mathrm{~N})$, the tribological properties of LP were significantly improved by adding BDS and NA-BDS-OLA. These results imply that an LP lubricant film forms at a low load and is easily damaged at a high load [35], possibly owing to the increased friction and wear of the LP under a high load. BDS and NA-BDS-OLA can play a positive role in protecting the friction interfaces [36]; hence, they have favorable anti-friction and anti-wear effects, improving the LP tribological properties under a high load.
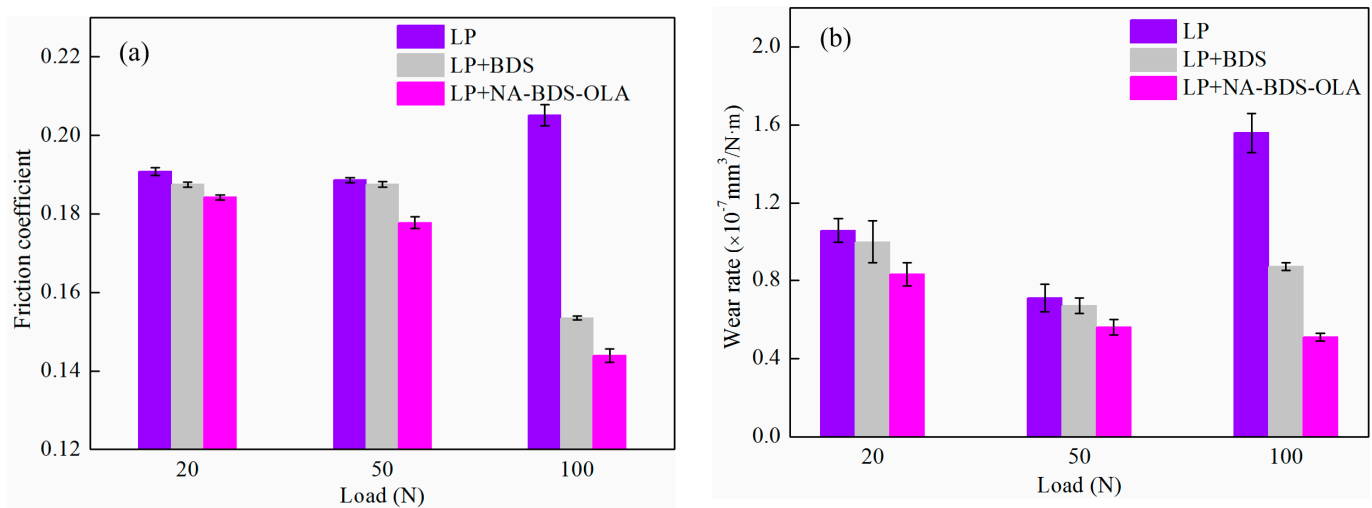

Figure 10. Evolutions of the (a) average friction coefficient and (b) wear rates for lubrication using BDS and NA-BDS-OLA in LP at different loads (soot content $=0.3 \mathrm{wt} \%$, speed $=50 \mathrm{~mm} / \mathrm{s}$, duration $=30 \mathrm{~min}$ ). 
Figure 11 shows FESEM images, optical micrographs, and the corresponding worn surface profiles of wear scars on upper balls lubricated using LP, LP + BDS, and LP + NA-BDS-OLA. Compared with the FESEM images in Figure 11a-c, the worn surfaces lubricated with LP exhibited many clear spalling pits. Numerous serious furrows and small pits were observed on the worn surface in the case of LP + BDS. For LP + NA-BDS-OLA, the worn surface exhibited no spalling pits and shallower furrows. The surface roughness $R a$ of the worn surface decreased in the following order: $\mathrm{LP}>\mathrm{LP}+\mathrm{BDS}>\mathrm{LP}$ + NA-BDS-OLA. According to the optical micrographs in Figure 11a-c and the corresponding worn surface profiles of the wear scars in Figure 11d, the width and depth of the wear scars decreased in the following order: LP > LP + BDS > LP + NA-BDS-OLA. This indicates that the main type of wear in the case of lubrication with LP was fatigue wear [37], whereas for LP + BDS, the fatigue wear was reduced. However, abrasive wear was observed on the worn surface. Because BDS can fill the friction pairs and act as a balling bearing, the aggregation of BDS can cause abrasive wear [38,39]. Apart from the spacing and ball bearing effect, the carbon onion-like nanoparticles (NA-BDS-OLA) possibly alleviated the friction shearing through their exfoliating behavior [40], which is in accordance with the results shown in Figure 10.
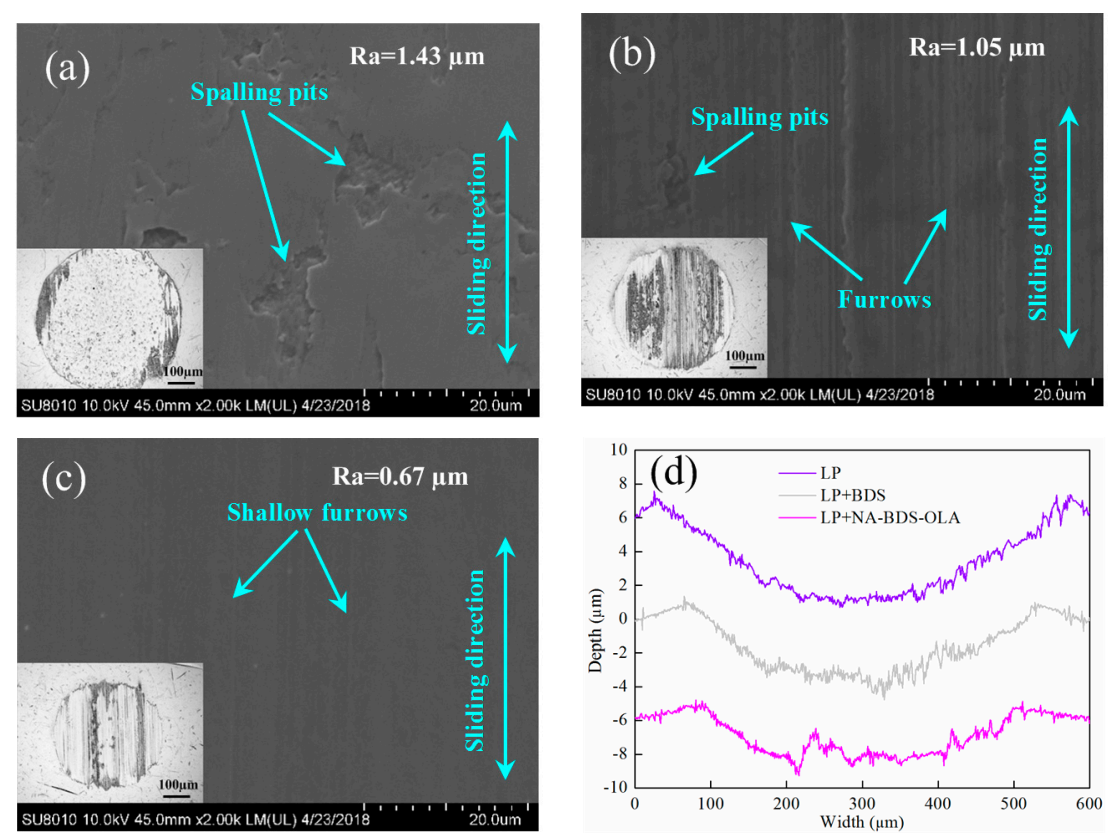

Figure 11. FESEM images and optical micrographs of wear scars on upper balls lubricated with (a) LP, (b) LP + BDS, and (c) LP + NA-BDS-OLA. (d) Corresponding worn surface profiles (soot content $=0.3$ wt $\%$, load $=100 \mathrm{~N}$, speed $=50 \mathrm{~mm} / \mathrm{s}$, duration $=30 \mathrm{~min}$ ).

\subsection{Lubrication Mechanisms}

Raman spectroscopy can be employed to obtain detailed information regarding the level of order in the structure by investigating the D and G peaks. The correlation between the structural changes of soot and the Raman spectroscopic parameters has been discussed in the literature [41,42]. Therefore, the order of soot before and after the friction test must be considered in Raman spectroscopy analyses. To investigate the differences in the friction reduction and wear resistance between BDS and NA-BDS, and between BDS and NA-BDS-OLA, we performed a Raman spectroscopy analysis of the wear surfaces. The Raman spectra of the worn surfaces of the upper balls are shown in Figure 12. 

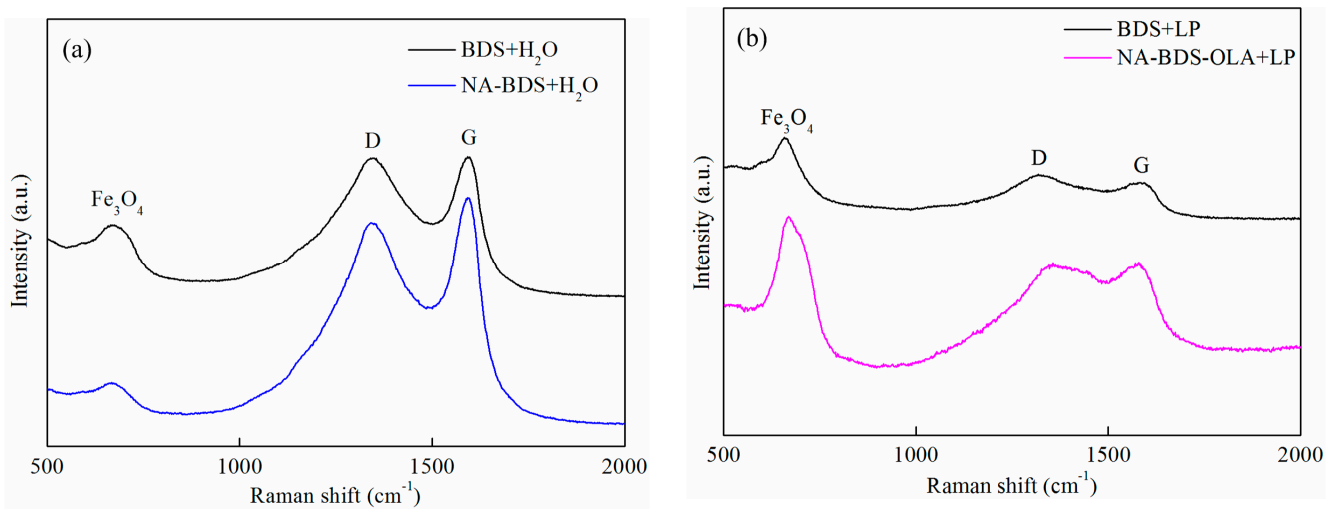

Figure 12. Raman spectra of the worn surfaces of upper balls lubricated using (a) BDS $+\mathrm{H}_{2} \mathrm{O}$ and $\mathrm{NA}-\mathrm{BDS}+\mathrm{H}_{2} \mathrm{O}$, and (b) BDS + LP and NA-BDS-OLA + LP.

The characteristic spectra of the D and G peaks were observed for the worn surfaces, indicating that the carbon nanoparticles deposited on the sliding surfaces formed a protective film. According to the Raman results in Figures 2 and 12, compared with the $\mathrm{I}_{\mathrm{D}} / \mathrm{I}_{\mathrm{G}}$ ratio for BDS (2.956), that of the worn surface lubricated using BDS in $\mathrm{H}_{2} \mathrm{O}$ (2.986) was not significantly increased, whereas that of the worn surface lubricated using NA-BDS in $\mathrm{H}_{2} \mathrm{O}$ (2.898) was significantly higher than that for NA-BDS (2.546). The peak at $660 \mathrm{~cm}^{-1}$ is attributed to $\mathrm{Fe}_{3} \mathrm{O}_{4}$, which formed a protective tribofilm through tribochemical reactions $[43,44]$. Moreover, the $\mathrm{I}_{\mathrm{D}} / \mathrm{I}_{\mathrm{G}}$ ratio for $\mathrm{BDS}(2.956)$ was similar to that of the worn surface lubricated using BDS in LP (2.927). However, the $\mathrm{I}_{\mathrm{D}} / \mathrm{I}_{\mathrm{G}}$ ratio for the worn surface lubricated using NA-BDS-OLA in LP was 2.700, which was higher than that for NA-BDS-OLA (2.559). An $\mathrm{Fe}_{3} \mathrm{O}_{4}$ $\left(660 \mathrm{~cm}^{-1}\right)$ tribofilm was created during the sliding [45]. These results imply that the formed $\mathrm{Fe}_{3} \mathrm{O}_{4}$ is capable of acting as a lubricious oxide. In contrast to BDS, NA-BDS and NA-BDS-OLA were prone to being exfoliated, generating isolated graphitic layers under a high load, which reduced the friction and wear [40].

According to the foregoing analysis, BDS can provide spacing and act as a ball bearing between the rubbed surfaces. However, NA-BDS and NA-BDS-OLA are structurally similar to onion-like carbon and have significantly higher degrees of graphitization order than BDS. The lubrication mechanisms of NA-BDS as a lubricant additive to $\mathrm{H}_{2} \mathrm{O}$ and NA-BDS-OLA as a lubricant additive to LP can be summarized as follows: First, both types of soot can penetrate into the friction pairs and be deposited on the sliding surface, thereby playing a positive role in reducing the direct contact between the micro-convex bodies during the friction experiment [38]. Second, both types of soot can act as a ball bearing between the friction pairs [31,46]. Finally, under a high load, the graphitic layers of both types of soot are prone to being exfoliated and adsorbed onto the friction interface, resulting in easy sliding and a good lubrication effect between the surfaces $[36,47]$.

\section{Conclusions}

NA-BDS treated with nitric acid and NA-BDS-OLA modified with OLA were used as lubricant additives to $\mathrm{H}_{2} \mathrm{O}$ and LP, respectively. Raman spectroscopy and FETEM indicated that both types of soot (NA-BDS and NA-BDS-OLA) exhibited a better order than BDS, having onion-like structures with a size of 35-40 nm. FTIR and particle-size distribution analysis revealed that NA-BDS and NA-BDS-OLA introduced strong hydrophilic and lipophilic groups, respectively, which reduced the average particle size.

To evaluate the tribological performance of the carbon onion-like nanoparticles derived from BDS, the tribological properties of NA-BDS in $\mathrm{H}_{2} \mathrm{O}$ and NA-BDS-OLA in LP were investigated. We found that the carbon onion-like structure of the two types of soot reduced the friction coefficients and wear rates. The tribological mechanisms can be divided into three mechanisms: (a) a spacing effect, where both types of soot act as spacers between the contact surfaces; (b) a ball bearing effect, in which both 
types of soot create a rolling between the friction pairs; and (c) an exfoliation effect, where a high load contributes to the formation of exfoliated graphitic layers from the two types of soot during sliding. These graphitic layers can be adsorbed onto the friction surfaces, resulting in easy sliding.

Author Contributions: Conceptualization, C.L., M.L., and X.H.; formal analysis, C.L. and Q.Z.; funding acquisition, M.L. and X.H.; investigation, C.L. and W.F.; methodology, C.L. and B.W.; writing-original draft, C.L.; writing-review and editing, M.L., X.W., and X.H.; all authors read and approved the final version of the manuscript.

Funding: This research was funded by the National Natural Science Foundation of China (Grant No. 51675153), Major Science and Technology Special Project in Anhui (Grant No. 17030901084), Anhui Province University Natural Science Research Project (Grant No. KJ2017A447 and KJ2019A0678), and School-level Scientific Research Projects of Chaohu University (Grant No. XLZ-201907).

Acknowledgments: The authors would like to thank Kunhong Hu and Enzhu Hu of Hefei University for their assistance in the FESEM test.

Conflicts of Interest: The authors declare no conflict of interest.

\section{References}

1. Palash, S.M.; Masjuki, H.H.; Kalam, M.A.; Atabani, A.E.; Rizwanul Fattah, I.M.; Sanjid, A. Biodiesel production, characterization, diesel engine performance, and emission characteristics of methyl esters from Aphanamixis polystachya oil of Bangladesh. Energy Convers. Manag. 2015, 91, 149-157. [CrossRef]

2. Singh, V.; Bux, F; Sharma, Y.C. A low cost one pot synthesis of biodiesel from waste frying oil (WFO) using a novel material, $\beta$-potassium dizirconate $\left(\beta-\mathrm{K}_{2} \mathrm{Zr}_{2} \mathrm{O}_{5}\right)$. Appl. Energy 2016, 172, 23-33. [CrossRef]

3. Kohse-Höinghaus, K.; Oßwald, P.; Cool, T.A.; Kasper, T.; Hansen, N.; Qi, F.; Westbrook, C.K.; Westmoreland, P.R. Biofuel combustion chemistry: From ethanol to biodiesel. Angew. Chem. Int. Ed. 2010, 49, 3572-3597. [CrossRef] [PubMed]

4. Lin, B.F.; Huang, J.H.; Huang, D.Y. Experimental study of the effects of vegetable oil methyl ester on DI diesel engine performance characteristics and pollutant emissions. Fuel 2009, 88, 1779-1785. [CrossRef]

5. Hu, E.Z.; Hu, X.G.; Liu, T.X.; Song, R.H.; Dearn, K.D.; Xu, H.M. Role of $\mathrm{TiF}_{3}$ catalyst in the tribological properties of biofuel soot-contaminated liquid paraffin. Tribol. Int. 2014, 77, 122-131. [CrossRef]

6. Salehi, F.M.; Khaemba, D.N.; Morina, A.; Neville, A. Corrosive-abrasive wear induced by soot in boundary lubrication regime. Tribol. Lett. 2016, 63, 19. [CrossRef]

7. Green, D.A.; Lewis, R.; Dwyer-Joyce, R.S. Wear effects and mechanisms of soot-contaminated automotive lubricants. Proc. Inst. Mech. Eng. Part J J. Eng. Tribol. 2006, 220, 159-169. [CrossRef]

8. Guo, M.F.; Cai, Z.B.; Zhang, Z.C.; Zhu, M.H. Characterization and lubrication performance of diesel soot nanoparticles as oil lubricant additives. RSC Adv. 2015, 5, 101965-101974. [CrossRef]

9. Joly-Pottuz, L.; Vacher, B.; Ohmae, N.; Martin, J.M.; Epicier, T. Anti-wear and friction reducing mechanisms of carbon nano-onions as lubricant additives. Tribol. Lett. 2008, 30, 69-80. [CrossRef]

10. Hirata, A.; Igarashi, M.; Kaito, T. Study on solid lubricant properties of carbon onions produced by heat treatment of diamond clusters or particles. Tribol. Int. 2004, 37, 899-905. [CrossRef]

11. Jung, Y.; Hwang, J.; Bae, C. Assessment of particulate matter in exhaust gas for biodiesel and diesel under conventional and low temperature combustion in a compression ignition engine. Fuel 2016, 165, 413-424. [CrossRef]

12. Savic, N.; Rahman, M.M.; Miljevic, B.; Saathoff, H.; Naumann, K.H.; Leisner, T.; Riches, J.; Gupta, B.; Motta, N.; Ristovski, Z.D. Influence of biodiesel fuel composition on the morphology and microstructure of particles emitted from diesel engines. Carbon 2016, 104, 179-189. [CrossRef]

13. Growney, D.J.; Mykhaylyk, O.O.; Middlemiss, L.; Fielding, L.A.; Derry, M.J.; Aragrag, N.; Lamb, G.D.; Armes, S.P. Is carbon black a suitable model colloidal substrate for diesel soot. Langmuir 2015, 31, 10358-10369. [CrossRef] [PubMed]

14. Kontou, A.; Southby, M.; Spikes, H.A. Effect of steel hardness on soot wear. Wear 2017, 390, 236-245. [CrossRef]

15. Hu, E.; Dearn, K.D.; Yang, B.X.; Song, R.H.; Xu, Y.F.; Hu, X.G. Tribofilm formation and characterization of lubricating oils with biofuel soot and inorganic fluorides. Tribol. Int. 2017, 107, 163-172. [CrossRef] 
16. Clague, A.D.H.; Donnet, J.B.; Wang, T.K.; Peng, J.C.M. A comparison of diesel engine soot with carbon black. Carbon 1999, 37, 1553-1565. [CrossRef]

17. Ferraro, G.; Fratini, E.; Rausa, R.; Fiaschi, P.; Baglioni, P. Multiscale characterization of some commercial carbon blacks and diesel engine soot. Energy Fuels 2016, 30, 9859-9866. [CrossRef]

18. Li, C.; Song, H.; Zhang, J.; Wu, B.; Zhang, Q.Q.; Zhuang, Y.; Hu, X.G. Novel approach for improved tribological behavior of biodiesel soot in liquid paraffin. China Pet. Process. Petrochem. Technol. 2019, 21, 62-70.

19. Hu, E.Z.; Hu, X.G.; Liu, T.X.; Liu, Y.M.; Song, R.H.; Chen, Y.Z. Investigation of morphology, structure and composition of biomass-oil soot particles. Appl. Surf. Sci. 2013, 270, 596-603. [CrossRef]

20. Li, C.; Wei, D.Z.; Zhuang, Y.; Song, R.H.; Hu, X.G. Effect of biodiesel soot on tribological behavior of liquid paraffin. China Pet. Process. Petrochem. Technol. 2018, 20, 106-113.

21. Boehman, A.L.; Song, J.; Alam, M. Impact of biodiesel blending on diesel soot and the regeneration of particulate filters. Energy Fuels 2005, 19, 1857-1864. [CrossRef]

22. Zhang, Y.; Zhang, R.; Rao, L.; Kim, D.; Kook, S. The influence of a large methyl ester on in-flame soot particle structures in a small-bore diesel engine. Fuel 2017, 194, 423-435. [CrossRef]

23. Deng, X.; Mammen, L.; Butt, H.J.; Vollmer, D. Candle soot as a template for a transparent robust superamphiphobic coating. Science 2012, 335, 67-70. [CrossRef] [PubMed]

24. Thomson, M.; Mitra, T. A radical approach to soot formation. Science 2018, 361, 978-979. [CrossRef] [PubMed]

25. Mutyala, K.C.; Wu, Y.A.; Erdemir, A.; Sumant, A.V. Graphene-MoS 2 ensembles to reduce friction and wear in DLC-Steel contacts. Carbon 2019, 146, 524-527. [CrossRef]

26. Wang, W.Z.; Huang, P. Study on the lubrication state of frictional pairs with different surface roughness based on Stribeck curves. Tribol. 2004, 24, 254-257.

27. Xu, Y.F.; Liu, Z.C.; Dearn, K.D.; Dong, Y.H.; You, T.; Hu, X.G. Thermo-tribological behaviour of microgels for improved aqueous lubrication for steel/UHMWPE contact. Tribol. Int. 2019, 130, 63-73. [CrossRef]

28. Xu, Y.F.; Yu, J.Y.; Dong, Y.H.; You, T.; Hu, X.G. Boundary lubricating properties of black phosphorus nanosheets in polyalphaolefin oil. J. Tribol. 2019, 141, 072101. [CrossRef]

29. Rosenkranz, A.; Freeman, L.; Fleischmann, S.; Lasserre, F.; Fainman, Y.; Talke, F.E. Tip-enhanced Raman spectroscopy studies of nanodiamonds and carbon onions. Carbon 2018, 132, 495-502. [CrossRef]

30. Du, S.N.; Sun, J.L.; Wu, P. Preparation, characterization and lubrication performances of graphene oxide-TiO nanofluid in rolling strips. Carbon 2018, 140, 338-351. [CrossRef]

31. Wei, J.X.; Cai, M.R.; Zhou, F.; Liu, W.M. Candle soot as particular lubricant additives. Tribol. Lett. 2014, 53, 521-531. [CrossRef]

32. Klokkenburg, M.; Hilhorst, J.; Erne, B.H. Surface analysis of magnetite nanoparticles in cyclohexane solutions of oleic acid and oleylamine. Vib. Spectro. 2007, 43, 243-248. [CrossRef]

33. Zhang, G.Q.; Xu, Y.; Xiang, X.Z.; Zheng, G.L.; Zeng, X.Q.; Li, Z.P.; Ren, T.H.; Zhang, Y.D. Tribological performances of highly dispersed graphene oxide derivatives in vegetable oil. Tribol. Int. 2018, 126, 39-48. [CrossRef]

34. Xiao, H.P.; Liu, S.H.; Wang, D.G.; Chen, Y. Abrasion-corrosion behaviors of steel-steel contact in seawater containing abrasive particles. Tribol. Trans. 2018, 61, 12-18. [CrossRef]

35. Wei, J.X.; Yao, M.H.; Cai, M.R.; Zhou, F. Tribological properties of cetyltrimethyl ammonium bromide modified candle soot as effective lubricant additive in oil. Tribology 2014, 34, 428-436.

36. Fan, X.Q.; Li, W.; Fu, H.M.; Zhu, M.H.; Wang, L.P.; Cai, Z.B.; Liu, J.H.; Li, H. Probing the function of solid nanoparticle structure under boundary lubrication. ACS Sustain. Chem. Eng. 2017, 5, 4223-4233. [CrossRef]

37. Liu, Y.R.; Hu, K.H.; Hu, E.Z.; Guo, J.H.; Han, C.L.; Hu, X.G. Double hollow $\mathrm{MoS}_{2}$ nano-spheres: Synthesis, tribological properties, and functional conversion from lubrication to photocatalysis. Appl. Surf. Sci. 2017, 392, 1144-1152. [CrossRef]

38. Alazemi, A.A.; Etacheri, V.; Dysart, A.D.; Stacke, L.E.; Pol, V.G.; Sadeghi, F. Ultrasmooth submicrometer carbon spheres as lubricant additives for friction and wear reduction. ACS Sustain. Chem. Eng. 2015, 7, 5514-5521. [CrossRef]

39. Penchaliah, R.; Harvey, T.J.; Wood, R.J.K.; Nelson, K.; Powrie, H.E.G. The effects of diesel contaminants on tribological performance on sliding steel on steel contacts. Proc. Inst. Mech. Eng. Part J J. Eng. Tribol. 2011, 225, 779-797. [CrossRef] 
40. Huang, G.W.; Yu, Q.L.; Ma, Z.F.; Cai, M.R.; Zhou, F.; Liu, W.M. Fluorinated candle soot as the lubricant additive of perfluoropolyether. Tribol. Lett. 2017, 65, 28. [CrossRef]

41. Cao, Z.F.; Xia, Y.Q. Study on the preparation and tribological properties of fly ash as lubricant additive for steel/steel pair. Tribol. Lett. 2017, 65, 104. [CrossRef]

42. Knauer, M.; Carrara, M.; Rothe, D.; Niessner, R.; Ivleva, N.P. Changes in structure and reactivity of soot during oxidation and gasification by oxygen, studied by micro-Raman spectroscopy and temperature programmed oxidation. Aerosol Sci. Technol. 2009, 43, 1-8. [CrossRef]

43. Zhang, X.; Niu, Y.A.; Meng, X.D.; Li, Y.; Zhao, J.P. Structural evolution and characteristics of the phase transformations between $\alpha-\mathrm{Fe}_{2} \mathrm{O}_{3}, \mathrm{Fe}_{3} \mathrm{O}_{4}$ and $\gamma-\mathrm{Fe}_{2} \mathrm{O}_{3}$ nanoparticles under reducing and oxidizing atmospheres. CrystEngComm 2013, 15, 8166-8172. [CrossRef]

44. Zin, V.; Agresti, F.; Barison, S.; Litti, L.; Fedele, L.; Meneghetti, M.; Fabrizio, M. Effect of external magnetic field on tribological properties of goethite (a-FeOOH) based nanofluids. Tribol. Int. 2018, 127, 341-350. [CrossRef]

45. Shi, B.; Guo, J.H.; Cao, X.A.; Hu, E.Z.; Hu, K.H. Effects of carbon soot from the combustion of diesel fuels on the tribological properties of lubricating oil and diesel fuels. Ind. Lubr. Tribol. 2018, 70, 532-537. [CrossRef]

46. Zhang, Z.C.; Cai, Z.B.; Peng, J.F.; Zhu, M.H. Comparison of the tribology performance of nano-diesel soot and graphite particles as lubricant additives. J. Phys. D Appl. Phys. 2015, 49, 045304. [CrossRef]

47. Ma, T.B.; Wang, L.F.; Hu, Y.Z.; Li, X.; Wang, H. A shear localization mechanism for lubricity of amorphous carbon materials. Sci. Rep. 2014, 4, 3662. [CrossRef]

(C) 2019 by the authors. Licensee MDPI, Basel, Switzerland. This article is an open access article distributed under the terms and conditions of the Creative Commons Attribution (CC BY) license (http://creativecommons.org/licenses/by/4.0/). 